\title{
Registered Nurses' Perception about Pain Management of Hospitalized Patients in One of the Governmental Hospitals in Dubai, UAE: A Cross-Sectional Study
}

\author{
Noora Abdulmajid AbuBaker Nezar Ahmed Salim Rennie Joshua Ambily Jose
}

In-Service Education Department, Dubai hospital, Dubai Health Authority, Dubai, United Arab Emirates

\section{Keywords}

Perception · Nurses' attitudes · Knowledge · KASRP · United Arab Emirates

\begin{abstract}
Background: Chronic and acute pain are highly prevalent, especially among hospitalized surgical patients, patients with cancer, and general medical inpatients. More than 50\% of patients experience significant pain. Health professionals' knowledge and attitude concerning pain management have often been referred to as insufficient. This study explored the attitudes and knowledge of nurses working in one of the government hospitals in the UAE, with regard to pain management. Methods: A quantitative, descriptive, cross-sectional design was used to examine nurses' perception (knowledge and attitude) about pain using the Nurses' Knowledge and Attitudes Survey Regarding Pain (NKASRP). We targeted the nursing field in order to assess nurses' perceptions of pain management. A convenience sample of 200 nurses working at one of the government hospitals in the UAE participated in this study. Results: Participants who scored $<75 \%$ were considered to have poor knowledge and a nonstandard attitude. Participants who scored $>75 \%$ were
\end{abstract}

considered to have adequate knowledge and a positive attitude. The study revealed that the knowledge and attitude percentage means of correct answers about pain management was $61 \%$ (SD: $\pm 11.97 \%$; $95 \%$ Cl 59.33-62.6\%). Inadequate knowledge and attitude featured in $89.5 \%$ and adequate knowledge and attitude in $10.5 \%$ of all participants. Previous pain management education experience was statistically significant $p<0.05$. Conclusion and Recommendation: This study showed that nurses reflected an inadequate knowledge and attitude regarding pain management. Nurses' perception about pain management was higher among younger staff than those with longer experience. Pain management education has an impact on knowledge and attitude. There is a need to follow innovative approaches in training. Pain management education is an essential part of the nursing orientation program and should be conducted throughout the year to target all nurses. New evidencebased approaches to pain management among nurses should be explored and tested, using the NKASRP as a baseline and follow-up measure. @ 2019 The Author(s) Published by S. Karger AG, Basel

\begin{tabular}{ll}
\hline KARGER & $\begin{array}{l}\text { (c) } 2019 \text { The Author(s) } \\
\text { Published by S. Karger AG, Basel }\end{array}$ \\
E-Mail karger@karger.com & $\begin{array}{l}\text { This article is licensed under the Creative Commons Attribution- } \\
\text { NonCommercial-NoDerivatives 4.0 International License (CC BY- } \\
\text { NC-ND) (http://www.karger.com/Services/OpenAccessLicense). } \\
\text { Wwwage and distribution for commercial purposes as well as any dis- } \\
\text { tribution of modified material requires written permission. }\end{array}$
\end{tabular}

Nezar Ahmed Salim

Dubai Health Authority, Education Department

Dubai Hospital, Al-Baraha Street

Dubai (United Arab Emirates)

E-Mail Nezar_dubai30@yahoo.com 


\section{Introduction}

Chronic and acute pain are highly prevalent, especially among hospitalized surgical patients, patients with cancer, and general medical inpatients. More than $50 \%$ of patients experience significant pain [1]. Reducing the pain and suffering of patients is essential to delivering quality care. Pain affects quality of life, physical functioning, social relationships, and mental health. Pain is often accompanied by other symptoms, such as fatigue, sleep disturbance, loss of appetite, and anxiety [2]. Therefore, if pain is left untreated, it can have complex side effects, including higher costs and longer hospital stay, that can interfere with the patient's daily life [3]. Pain is the most common symptom experienced by cancer patients [4]. The prevalence of cancer pain is estimated at 39.3\% among patients after curative treatment, 55\% during anticancer treatment, and $66.4 \%$ in advanced, metastatic, or terminal disease [5]. Clinically, pain as the fifth vital sign has been ascertained to be more complex in terms of assessment, evaluation, and management than originally expected [6]. Inadequate treatment has been mostly linked to the failure of health care workers' to assess patients' pain and intervene appropriately [7].

Nurses play an essential role in developing pain management plans. Inadequate pain relief can be attributed to nurses' lack of knowledge about pain assessment and management and the incidence of narcotic addiction. As well as negative attitudes regarding therapeutic levels of analgesia, the undertreatment of pain increases patient suffering and how much pain they experience. A lack of knowledge about pain and its features is a common barrier to effective pain management [8]. The World Health Organization (WHO) recommended that governments should develop and implement national policies and programs of pain relief. Moreover, in 1969, the WHO designated an educational program referred to as the threestep analgesic ladder. Nurses play an important role as they are the professionals most frequently in contact with patients receiving different levels of care. This puts the nurses in a unique position to identify those patients that experience pain and assess and manage this pain effectively [9].

Additional studies have found that nurses in Turkey [10], Italy [11], Iran [12], and Saudi Arabia [13] have inadequate knowledge and attitude regarding pain, as measured by the Nurses' Knowledge and Attitudes Survey Regarding Pain (NKASRP). Nurses in the USA are shown to score better, but many do not meet the $80 \%$ passing score [14]. Since many studies have been conducted worldwide, this study was conducted in the UAE to assess nurses' knowledge and attitudes toward pain control. The results were compared with other studies and an action plan was suggested.

\section{Main Goal}

Our aim was to measure the mean of the percentage of total correct answers, and then assess the level of knowledge and attitudes of nurses toward pain management in one of the governmental hospitals in Dubai, UAE, in March 2019.

The SMART objective is that, by the end of October 2019 , a level of nurses' perception of up to $85 \%$ will have been accomplished by implementing a training program in one of the governmental hospitals in Dubai, UAE.

\section{Methodology}

This study was carried out in a government hospital in Dubai, UAE, in March 2019. It is a cross-sectional, descriptive study. A convenience sample was selected to participate in this study. Two hundred nurses met the inclusion criteria. The nurses who were selected had $>1$ year of experience and fully understand and speak English. Data collection was carried out using a structured, selfadministered instrument, the Knowledge and Attitudes Survey Regarding Pain (KASRP). This consists of 39 questions: 22 true/ false, 15 multiple choice, and 2 scenarios. The tool was identified as discriminating between levels of expertise. It was developed by Betty Ferrell in 1987. She has been contacted by e-mail to get permission to use and translate the tool. The tool is available on the City of Hope website (http://prc.coh.org) [15].

Nurses who answered $\geq 75 \%$ of the knowledge and attitude questions correctly were considered as having adequate knowledge and a good attitude. Nurses who scored $<75 \%$ were considered as having an inadequate knowledge and attitude [16].

\section{Knowledge of Pain}

Knowledge of pain is operationally defined here as the nurses' knowledge about assessment as well as nonpharmacological and pharmacological management of pain as measured with the pain tool developed by McCaffery and Ferrell [17].

\section{Pain Intensity Rating}

A numerical rating index ranging from 0 to 10 was used: 0 , no pain; $1-3$, mild pain; $4-6$, moderate pain; $7-9$, severe pain; and 10 , the "worst pain imaginable" [16].

The questionnaire was given to the participants who met the inclusion criteria. An information sheet was attached to the questionnaire explaining the purpose of the study. The nurses ensured that confidentiality and privacy of the answers were maintained. No names, phone numbers, or identification were included. The coding, entry, and analysis of data were conducted by using SPSS v20 software and Microsoft Excel. The data were tested at a 95\% 
level of significance, and differences with a $p$ value $<0.05$ were considered significant. In addition, Fisher's exact test was used to find the association of demographical data and conceptual variables.

\section{Results}

\section{Demographical Data}

The sample consisted of 200 participants; $10 \%$ were male and $90 \%$ female. Among the participants, $67 \%$ were married, $32 \%$ were single, and $1 \%$ other. In terms of the nationality profile, $46 \%$ of the respondents were Indians, 42.5\% were Filipinos, $7.5 \%$ were Arabs, and $4 \%$ were other nationalities.

The study revealed that the majority of participants had a bachelor's degree (85\%); $8 \%$ had a master's degree and $7 \%$ had a diploma. Regarding education related to pain management, $62.5 \%$ had received training and $37.5 \%$ had never attended any sessions related to pain management. The mean age of the participants was 35.43 (SD \pm 8.134 ) years (Table 1 ). The mean experience was 11.88 ( $\mathrm{SD} \pm 6.289$ ) years (median 10 years). Knowledge and attitude about pain management mean score of correct answers was 61\% (SD $\pm 11.97 \%$; 95\% CI 59.33-62.6\%; Table 2).

Table 3 shows that only $10.5 \%$ of the participants had an adequate knowledge and attitude about pain and $89.5 \%$ had inadequate knowledge and attitude about pain.

Fisher's exact test showed that there were no significant differences in knowledge according to categorical variables (gender, marital status, nationality, level of education, and age). The pain management program showed statistically significant results with $p<0.05$. Similarly, nursing experience reflected statistical significance with $p<0.05$ (Table 4).

\section{Discussion}

Pain management is considered an important aspect of nursing which should not be neglected. This study found that nurses working in one of the government hospitals in Dubai, UAE, lacked the knowledge and attitude to provide optimal pain management. Inadequate knowledge was distributed among $89.5 \%$ and good knowledge only among $10.5 \%$. These results revealed that the nurses had an inadequate knowledge and attitude when compared to other studies conducted worldwide. For instance, the mean percentage of correct answers was $66.6 \%$
Table 1. Participants' demographical data

\begin{tabular}{llrr}
\hline & & $n$ & $\%$ \\
\hline Gender & Male & 20 & 10.0 \\
& Female & 180 & 90.0 \\
\hline Marital status & Single & 64 & 32.0 \\
& Married & 134 & 67.0 \\
& Others & 2 & 1.0 \\
\hline Nationality & Arab & 15 & 7.5 \\
& Filipino & 85 & 42.5 \\
& Indian & 92 & 46.0 \\
& Others & 8 & 4.0 \\
\hline Level of education & Diploma & 14 & 7.0 \\
& Bachelor's & 170 & 85.0 \\
& Master's & 16 & 8.0 \\
\hline Pain management education & Yes & 125 & 62.5 \\
& No & 75 & 37.5 \\
\hline Age, years (mean \pm SD) & $35.43 \pm 8.134$ & & \\
Experience, years (mean \pm SD) & $11.88 \pm 6.289$ & & \\
\hline
\end{tabular}

Table 2. Mean of correct answers

\begin{tabular}{llll}
\hline & Mean \pm SD & \multicolumn{2}{l}{$95 \%$ Confidence interval } \\
\cline { 3 - 4 } & & lower & upper \\
\hline Mean of correct answers & $61 \% \pm 11.97$ & $59.33 \%$ & $62.6 \%$ \\
\hline
\end{tabular}

Table 3. Distribution of good and inadequate knowledge among nurses

\begin{tabular}{lrr}
\hline & $n$ & $\%$ \\
\hline Staff who displayed good knowledge & 21 & 10.5 \\
Staff who displayed inadequate knowledge & 179 & 89.5 \\
\hline
\end{tabular}

in a study from Iran [12] and $64.6 \%$ in a study from the USA [14]. However, the situation was better than in some other countries, e.g., $42 \%$ in a study from Saudi Arabia [18] and 35\% in a study from Turkey [10].

The sample used in this study was heterogeneous, i.e., it consisted of nurses from different cultural backgrounds (the majority of nurses are expatriates). The results were similar to those of studies conducted in Iran [12] and Saudi Arabia [13] regarding the impact of such diversity on NKASRP. No significant relationship was found. In other 
Table 4. Association of nurses' knowledge and attitude with other factors

\begin{tabular}{|c|c|c|c|c|}
\hline & Group & Inadequate $^{\mathrm{a}}$ & Adequate $^{b}$ & $p$ value \\
\hline \multirow[t]{2}{*}{ Gender } & Male & $95.0 \%$ & $5.0 \%$ & \multirow[t]{2}{*}{0.347} \\
\hline & Female & $88.8 \%$ & $11.23 \%$ & \\
\hline \multirow[t]{2}{*}{ Marital status } & Single & $88.9 \%$ & $11.1 \%$ & \\
\hline & Married & $90.3 \%$ & $9.7 \%$ & \\
\hline \multirow{3}{*}{$\begin{array}{l}\text { Level of } \\
\text { education }\end{array}$} & Diploma & $92.9 \%$ & $7.1 \%$ & \multirow[t]{3}{*}{0.893} \\
\hline & Bachelor's & $88.8 \%$ & $11.2 \%$ & \\
\hline & Master's & $93.3 \%$ & $6.7 \%$ & \\
\hline \multirow{2}{*}{$\begin{array}{l}\text { Pain management } \\
\text { education }\end{array}$} & Yes & $80.1 \%$ & $19.9 \%$ & \multirow[t]{2}{*}{0.035} \\
\hline & No & $93.3 \%$ & $6.7 \%$ & \\
\hline \multirow[t]{3}{*}{ Nationality } & Jordan & $93.3 \%$ & $6.7 \%$ & \multirow[t]{3}{*}{0.755} \\
\hline & Philippines & $87.1 \%$ & $12.9 \%$ & \\
\hline & India & $91.3 \%$ & $8.7 \%$ & \\
\hline \multirow{6}{*}{$\begin{array}{l}\text { Years of nursing } \\
\text { experience }\end{array}$} & $<5$ & $77.3 \%$ & $22.7 \%$ & \multirow[t]{6}{*}{0.015} \\
\hline & $5-9$ & $87.1 \%$ & $12.9 \%$ & \\
\hline & $10-15$ & $91.5 \%$ & $8.5 \%$ & \\
\hline & $15-20$ & $100.0 \%$ & $0.0 \%$ & \\
\hline & $20-25$ & $90.9 \%$ & $9.1 \%$ & \\
\hline & $>25$ & $100.0 \%$ & $0.0 \%$ & \\
\hline \multirow[t]{4}{*}{ Age, years } & $20-29$ & $89.2 \%$ & $10.8 \%$ & \multirow[t]{4}{*}{0.577} \\
\hline & $30-39$ & $87.0 \%$ & $13.0 \%$ & \\
\hline & $40-49$ & $94.9 \%$ & $5.1 \%$ & \\
\hline & $50-60$ & $92.3 \%$ & $7.7 \%$ & \\
\hline
\end{tabular}

${ }^{a}$ Nurses with an inadequate knowledge and attitude about pain management.

b Nurses with an adequate knowledge and attitude about pain management.

words, nurse competency about pain management did not vary according to culturally related factors, unlike another study conducted by Alqahtani and Jones [18] who found significant differences in knowledge and attitude scores among culturally heterogeneous nurse populations.

The results highlighted that traditional pain management education of nurses is effective. There was a statistically significant difference between those who had received pain management education and those who had not. These findings were similar to those of Foyle [19] who found significant relationship between pain management education and contextual variables. Meanwhile, no significant correlation of level of education with knowledge and attitude was revealed. Another study [20] produced controversial results, i.e., that the level of education enhanced knowledge and built a positive attitude

Perception of Pain by Registered Nurses towards pain management among nurses. Most of the participants who had an inadequate perception about pain were holders of a bachelor's degree. Surprisingly, the holders of a diploma scored higher than nurses who had a master's degree, in contrast to other studies showing that a higher level of education has an effect on nurses' knowledge and attitude [21]. Marital status and gender showed no statistically significant differences.

With regard to nursing experience, it was expected that the knowledge and attitude about pain management would increase along with longer experience, but the result showed that nurses with $>10$ years' experience had a poorer perception than staff with only 5-10 years' experience. Similar results have been reported in other studies which found that as nurses' experience increases, the pain management scores decrease [22].

We acknowledge the limitations of this study. The sample of this study was heterogeneous. The nurses had different cultural and educational backgrounds. In addition, the data were collected from a convenience sample, which significantly limits generalizability and comparisons with other parts of the world.

\section{Conclusion}

This study showed that the nurses' knowledge and attitudes regarding pain management were inadequate. Nurses' perception about pain management was higher among younger staff than those with longer experience. Pain management education has an impact on knowledge and attitudes. There is a need to introduce innovative approaches in training. Pain management education is an essential part of the nursing orientation program, should be offered throughout the year, and target all nurses. New evidence-based approaches to pain management among nurses should be explored and tested, using the NKASRP as a baseline.

\section{Acknowledgement}

The authors would like to thank the participants who dedicated their time to enroll in our study.

\section{Statement of Ethics}

Ethical approval was obtained from the Dubai scientific research ethics committee of the Dubai Health Authority (DHA) prior to data collection. All participants signed a consent form. 


\section{Disclosure Statement}

The authors declare that they do not have conflicts of interest. All authors read and approved the submitted version and confirm that the manuscript is our own original work.

\section{Funding Sources}

This study was not funded by any organization.

\section{Author Contributions}

N.A.A. was the principal investigator, N.A.S. was the data analyst and corresponding author, and R.J. and A.J. collected the data.

\section{References}

1 Lin RJ, Reid MC, Liu LL, Chused AE, Evans AT. The Barriers to High-Quality Inpatient Pain Management: A Qualitative Study. Am J Hosp Palliat Care. 2015 Sep;32(6):594-9.

2 Green CR, Hart-Johnson T, Loeffler DR. Cancer-related chronic pain: examining quality of life in diverse cancer survivors. Cancer. 2011 May;117(9):1994-2003.

3 Keefe FJ, Ahles TA, Sutton L, Dalton J, Baucom D, Pope MS, et al. Partner-guided cancer pain management at the end of life: a preliminary study. J Pain Symptom Manage. 2005 Mar;29(3):263-72.

4 Vallerand AH, Templin T, Hasenau SM, Riley-Doucet C. Factors that affect functional status in patients with cancer-related pain. Pain. 2007 Nov;132(1-2):82-90.

5 van den Beuken-van Everdingen MH, de Rijke JM, Kessels A, Schouten HC, van Kleef M, Patijn J. Prevalence of pain in patients with cancer: a systematic review of the past 40 years. Ann Oncol. 2007;18(9):1437-49.

6 Morone NE, Weiner DK. Pain as the fifth vital sign: exposing the vital need for pain education. Clin Ther. 2013 Nov;35(11):1728-32.

7 Yava A, Çicek H, Tosun N, Özcan C, Yildiz D, Dizer B. Knowledge and attitudes of nurses about pain management in Turkey. Int J Caring Sci. 2013;6(3):494-505.

8 Kim MH, Park H, Park EC, Park K. Attitude and knowledge of physicians about cancer pain management: young doctors of South Korea in their early career. Jpn J Clin Oncol. 2011 Jun;41(6):783-91.
9 World Health Organization. Cancer pain relief: with a guide to opioid availability. 2nd ed [Internet]. 1996 [cited 2019 May 24]. Available from: http://apps.who.int/ iris/bitstream/10665/37896/1/9241544821. pdf.

10 Yildirim YK, Cicek F, Uyar M. Effects of pain education program on pain intensity, pain treatment satisfaction, and barriers in Turkish cancer patients. Pain Manag Nurs. 2009 Dec;10(4):220-8.

11 Bernardi M, Catania G, Lambert A, Tridello G, Luzzani M. Knowledge and attitudes about cancer pain management: a national survey of Italian oncology nurses. Eur J Oncol Nurs. 2007 Jul;11(3):272-9.

12 Shahriary S, Shiryazdi SM, Shiryazdi SA, Arjomandi A, Haghighi F, Vakili FM, et al. Oncology nurses' knowledge and attitudes regarding cancer pain management. Asian Pac J Cancer Prev. 2015;16(17):7501-6.

13 Eid T, Manias E, Bucknall T, Almazrooa A. Nurses' knowledge and attitudes regarding pain in Saudi Arabia. Pain Manag Nurs. 2014 Dec;15(4):e25-36.

14 Brant JM, Mohr C, Coombs NC, Finn S, Wilmarth E. Nurses' Knowledge and Attitudes about Pain: Personal and Professional Characteristics and Patient Reported Pain Satisfaction. Pain Manag Nurs. 2017 Aug; 18(4):214-23.

15 City of Hope [Internet]. Duarte (CA) [cited 2017 Oct 7]. Available from: http://prc.coh. org.
16 Dilie A, Mengistu D. Assessment of nurses knowledge, attitude, and perceived barriers to expressed pressure ulcer prevention practice in Addis Ababa government hospitals, Addis Ababa, Ethiopia, 2015. Adv Nurs. 2015;2015: $1-11$.

17 McCaffery M, Ferrell BR. Nurses' knowledge of pain assessment and management: how much progress have we made? J Pain Symptom Manage. 1997 Sep;14(3):175-88.

18 Alqahtani M, Jones LK. Quantitative study of oncology nurses' knowledge and attitudes towards pain management in Saudi Arabian hospitals. Eur J Oncol Nurs. 2015 Feb;19(1): 44-9.

19 Foyle L. Delivering Cancer and Palliative Care Education. Abingdon: Radcliffe Publishing; 2004.

20 Kheshti R, Namazi S, Mehrabi M, Firouzabadi D. Health Care Workers' Knowledge, Attitude, and Practice about Chronic Pain Management, Shiraz, Iran. Anesth Pain Med. 2016 Jul;6(4):e37270.

21 McNamara MC, Harmon D, Saunders J. Effect of education on knowledge, skills and attitudes around pain. Br J Nurs. 2012 Sep; 21(16):958-64

22 Ekim A, Ocakc1 AF. Knowledge and attitudes regarding pain management of pediatric nurses in Turkey. Pain Manag Nurs. 2013 Dec;14(4):e262-7. 